\title{
Fin development in stream- and hatchery-reared Atlantic salmon
}

\author{
Ryan M. Pelis*, Stephen D. McCormick \\ Conte Anadromous Fish Research Center, Biological Resources Division, USGS, P.O. Box 796, \\ Turners Falls, MA 01376, USA
}

Received 11 March 2002; received in revised form 4 November 2002; accepted 13 November 2002

\begin{abstract}
To determine the effect of development and environment on fin growth, we measured fin lengths of juvenile Atlantic salmon (Salmo salar) from two hatcheries (August, October and April-May), stream-reared fish (July and October) stocked as fry into two tributaries, and smolts from the main stem of the Connecticut River (May). For stream-reared parr, there was a linear relationship between the dorsal, caudal and anal fins with fork length, while the pectoral, pelvic and adipose fins exhibited a curvilinear relationship with fork length. Parr from a high gradient stream had larger caudal fins than fish from a low gradient stream, but other fins did not differ. Regression lines for the fins of stream-reared smolts were all linear when fin length was regressed against fork length. Stream-reared parr had larger pectoral, pelvic and anal fins than smolts of similar size while dorsal and caudal fin lengths did not differ. Regression equations formulated using the fins of stream-reared parr were used to calculate the percent difference $(100 \times$ observed fin length/expected $)$ in fin lengths between stream- and hatchery-reared parr. The pelvic, adipose, caudal and anal fins of hatchery-reared parr showed no signs of degeneration by the first sampling period 7 months after hatching, whereas degeneration in the pectoral $(13-20 \%)$ and dorsal $(15-18 \%)$ fins was evident at this time. By the end of the study, degeneration was present in every fin except the adipose, with the pectoral (35$65 \%)$ and dorsal $(32-58 \%)$ fins exhibiting the greatest amount of fin loss. All fins of hatchery-reared parr became shorter with time. There were minor differences in fin degeneration among parr from the two hatcheries, but the overall pattern of decreasing fin size was similar, indicating a common cause of fin degeneration. Comparison of stream- and hatchery-reared fish is a valuable means of determining the impact of captive environments on fin growth.

Published by Elsevier Science B.V.
\end{abstract}

Keywords: Atlantic salmon; Salmo salar; Fin growth; Fin degeneration

* Corresponding author. Present address: Physiology and Neurobiology, U-4156, University of Connecticut, 3107 Horsebarn Hill Rd., Storrs, CT 06269-4156, USA. Tel.: +1-860-486-4667; fax: +1-860-486-3303.

E-mail address: ryan.pelis@uconn.edu (R.M. Pelis). 


\section{Introduction}

Fin erosion is a serious and widespread problem affecting hatchery facilities throughout the world and may be a factor in reducing fish survival (Schneider and Nicholson, 1980). Poor survival within production hatcheries and after release is economically exhaustive and counterproductive. The problem of fin erosion is so extensive that it is often used as an identifier of recently stocked fish, and as an indicator of overall fish health. The dorsal and pectoral fins are most susceptible to degeneration within the hatchery environment due to interactions with abrasive surfaces and through aggressive contact with other fish (Abbott and Dill, 1985; Bosakowski and Wagner, 1994). Many other factors have been implicated in causing fin erosion including overcrowding, water quality, temperature, feed type, malnutrition, bacterial infection, handling, and exposure to excessive sunlight and environmental contaminants.

Atlantic salmon in the Connecticut River were extirpated in the mid-1800s primarily due to dam construction. For the last 25 years, a restoration program released hatcheryproduced smolts that originated primarily from the Penobscot River (Maine, USA). Since 1987, more than a million fry have been released annually into tributaries of the Connecticut River. Progeny of Connecticut River returns comprise the bulk of current fry releases, but introductions from outside stocks continued until 1995. Fry are released in May prior to first feeding and reside in streams for $2-3$ years prior to smolt migration. The survival of stocked fish, therefore, is imperative to restoration efforts, and may be reduced by poor fin quality at the time of stocking. Lowered return rates of adult Atlantic salmon have been attributed to fin erosion among hatchery-reared smolts (Johannsson, 1981). This may be directly correlated to an increased susceptibility to predation and reduced ability to capture prey (Schneider and Nicholson, 1980). Critical current speed for station holding in Atlantic salmon parr dramatically decreases upon removal of both pectoral fins (Arnold et al., 1991). The inability to maintain position on the stream bottom in fast moving water may reduce survival through an increase in energy demand and decrease in foraging capabilities.

The flexible life history strategy of Atlantic salmon may alter their susceptibility to fin erosion. Dorsal fin erosion has been shown to be more prevalent among sexually immature parr than mature individuals (Mork et al., 1989). Atlantic salmon fingerlings and smolts over 2 years of age are most prone to bacterial infections, which can lead to fin erosion (Schneider and Nicholson, 1980). Fin erosion often begins in late fall as water temperatures begin to decline with an abatement ensuing in the spring as ambient temperatures increase (Schneider and Nicholson, 1980). Finding a time point when hatchery fish are most susceptible to fin erosion is important in determining causative agents and establishing preventative measures. The purposes of this study were to determine the normal pattern of fin growth in Atlantic salmon, whether fin sizes differ among stream- and hatchery-reared fish, when differences occur and how they change over time.

\section{Materials and methods}

Stream-reared Atlantic salmon parr stocked as fry were sampled by electrofishing the Chickley River (Hawley, MA) and West Brook (Whately, MA), two tributaries of the 
Connecticut River, in July and October 1997. The stream gradients for the Chickley River and West Brook in the region of sampling were 19.0 and $8.5 \mathrm{~m} \mathrm{~km}^{-1}$, respectively. Stream-reared Atlantic salmon smolts were sampled in May 1998 during their downstream migration in the Connecticut River at Cabot Station (Turners Falls, MA), $198 \mathrm{~km}$ from the mouth of the river.

Hatchery-reared Atlantic salmon parr from the White River National Fish Hatchery (Bethel, VT) and Kensington State Salmon Hatchery (Kensington, CT) were sampled in August 1997, October 1997 and April-May 1998. At each hatchery, parr under 1 year of age were sampled at the first time point, and the same cohorts were subsequently sampled again in the fall and following spring upon becoming 1 year of age. Two-year-old smolts from the White River National Fish Hatchery were sampled during the April 1998 sampling period.

Fish from the Kensington hatchery hatched in January and were maintained on Silver Cup feed (Nelson \& Sons, Murray, UT) throughout the study. Prior to and during the August sampling period, Kensington parr were reared in two 8-ft-diameter tanks with densities approximating $4.1 \mathrm{~kg} \mathrm{~m}^{-3}\left(1470 \mathrm{fish}^{-3}\right)$. Difference in fin lengths between fish from the two 8-ft-diameter tanks was less than $6 \%$, which was not significant $(P>0.05$, Mann-Whitney $U$-test). Fish from both tanks were combined in early fall and the density at the October sampling period approximated $6.7 \mathrm{~kg} \mathrm{~m}^{-3}\left(930 \mathrm{fish} \mathrm{m}^{-3}\right)$. In January, when the fish were 1 year of age, they were transferred into a 20 -ft-diameter pond with a pool liner. By the April sampling date, the density in the rearing pond was $18.5 \mathrm{~kg}$ $\mathrm{m}^{-3}$ (370 fish $\mathrm{m}^{-3}$ ). The fish were kept on automatic feeders until they were transferred into the pond. The 8 - $\mathrm{ft}$ tanks and 20 - $\mathrm{ft}$ pond were kept outdoors in enclosed shelters.

Fish from the White River hatchery hatched in January and were fed with Atlantic Salmon Diet (Zeigler Bros., Gardners, PA). During the August and October sampling periods, parr were reared indoors in two 8-ft-diameter tanks with densities approximating $2.8 \mathrm{~kg} \mathrm{~m}^{-3}$ (1120 fish $\left.\mathrm{m}^{-3}\right)$ in August and $7.5 \mathrm{~kg} \mathrm{~m}^{-3}\left(1120 \mathrm{fish} \mathrm{m}^{-3}\right)$ in October. During the August and October sampling periods, difference in fin lengths between fish from the two 8-ft-diameter tanks was less than $7 \%$, which was not significant $(P>0.05$, Mann-Whitney $U$-test). In January, fish were combined into a 30 -ft-diameter concrete pond in an enclosed shelter. Density during the April sampling period was approximately $10.5 \mathrm{~kg} \mathrm{~m}^{-3}$ (280 fish $\mathrm{m}^{-3}$ ). Smolts were being reared in a 30 -ft-diameter concrete pond at a density of $17.3 \mathrm{~kg} \mathrm{~m}^{-3}$ (50 fish $\mathrm{m}^{-3}$ ) during the April sampling period. All fish were maintained on automatic feeders until they were moved into the larger ponds.

Water velocity measurements were taken from each tank and pond at the Kensington and White River hatcheries using a flowmeter. Measurements were taken at the wall of the tanks and ponds halfway up the water column. Velocity measurements were similar among individual tanks from each hatchery and ranged in values between 0.06 and 0.09 $\mathrm{m} \mathrm{s}^{-2}$. Water velocities in the ponds of each hatchery were similar as well $(0.17-0.22$ $\mathrm{m} \mathrm{s}^{-2}$ ).

All fish were anesthetized using tricaine methanesulfonate (100 $\mathrm{mg}^{-1} \mathrm{MS}-222$ buffered with $\mathrm{NaHCO}_{3}, \mathrm{pH}$ 7.0). Body weight (nearest $0.1 \mathrm{~g}$ ), fork length, and total length were recorded for each fish. Fins were measured as outlined in Bosakowski and Wagner (1994). All fins, excluding the adipose, were measured for the longest distance parallel to the fin rays. The adipose fin was measured for its total length from the anterior 
insertion to the posterior end. All fins were measured to the nearest $0.01 \mathrm{~mm}$ using digital calipers (Mitutoyo CD-6" CS).

Multiple linear regression analysis was used to determine whether fin lengths were similar among stream-reared parr from the Chickley River and West Brook [fin length= $\beta_{0}+\left(\beta_{1} \times\right.$ fork length $)+\left(\beta_{2} \times\right.$ location $)+\left(\beta_{3}\right.$ (fork length $\times$ location $\left.\left.)\right)\right]$. When the slopes of individual regression lines were equal (when $\beta_{3}=0$ ), multiple linear regression analysis [fin length $=\beta_{0}+\left(\beta_{1} \times\right.$ fork length $)+\left(\beta_{2} \times\right.$ location $\left.)\right]$ was used to compare intercepts of the regression lines. Mann-Whitney $U$-test was used to compare relative fin lengths (fin length/fork length) between stream-reared parr and smolts of similar size $(132-173 \mathrm{~mm}$
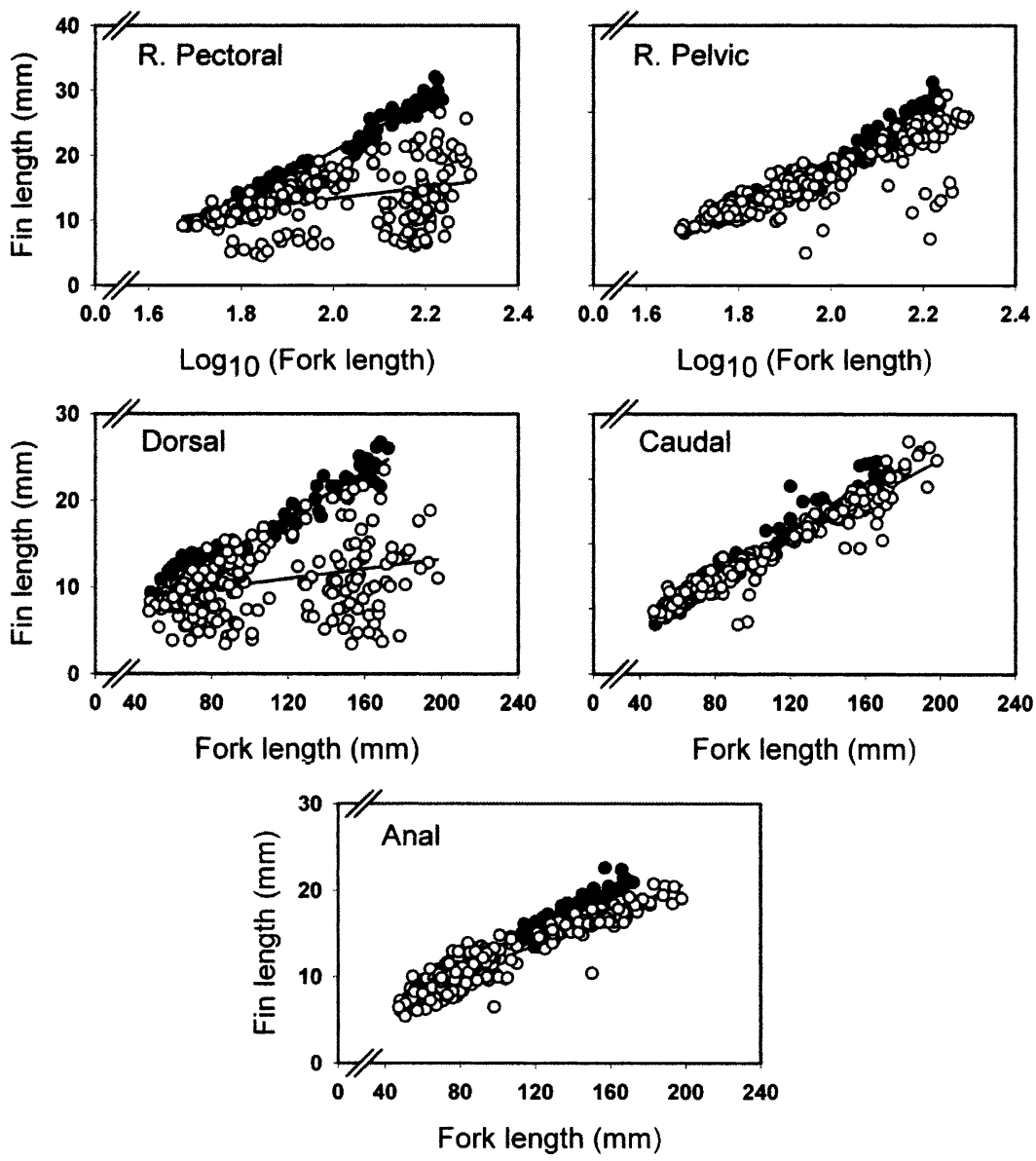

Fig. 1. Regression plots of fin length against fork length (LF; for the dorsal, caudal and anal fins) or the log transformation of fork length $\left(\log _{10}(\mathrm{LF})\right.$; for the right pectoral and right pelvic fins) for stream-reared Atlantic salmon parr $(N=120$; $)$ sampled from two Connecticut River tributaries in Massachusetts in July and October 1997, and hatchery-reared parr $(N=279$; $\bigcirc)$ from two New England hatcheries sampled in August and October 1997, and April-May 1998. 
fork length). Under the restricted size range, fin length displayed a linear relationship with fork length for both stream-reared parr and smolts.

Linear regression analysis of fin length against fork length and the log transformation of fork length were performed for stream-reared parr (Chickley River and West Brook combined) and smolts. The decision as to whether a regression line was linear or nonlinear was determined by comparing the residuals and correlation coefficients of fin length regressed against fork length and the log transformation of fork length. The linear regression equations produced from stream-reared Atlantic salmon parr were used to calculate the percent difference (observed fin length/expected) in fin lengths between stream- and hatchery-reared parr. Data of percent difference in fin lengths of hatcheryreared parr were rank transformed and a two-way Analysis of Variance (two-way ANOVA) was performed to examine the effects of location, date and their interaction on fin length. All statistical analyses were deemed significant at 5\% level of significance.

\section{Results}

At each sampling period, fish captured from the West Brook were larger on average than those captured from the Chickley River. Multiple linear regression analyses indicated that slopes and intercepts were equivalent among the pectoral, pelvic, dorsal, adipose and anal fins between parr from each stream $\left(\beta_{2}, \beta_{3} ; P>0.05\right)$. Analysis of caudal fin measurements, however, indicated significant differences (slopes of 0.199 vs. 0.171 for Chickley River and West Brook, respectively, $P<0.05)$, suggesting a greater relative caudal fin size among fish from the Chickley River. To make comparisons between stream- and hatchery-reared parr, all fin measurements of stream-reared parr were grouped.

When grouped (Chickley River and West Brook combined), the dorsal, caudal and anal fins exhibited a linear relationship with fork length (Fig. 1 and Table 1). Higher coefficients of determination $\left(r^{2}=0.90\right)$ for the pectoral, pelvic and adipose fins against the log transformation of fork length suggested a curvilinear relationship for these fins.

Table 1

Linear regression equations of fin length against fork length (LF) or the log transformation of fork length $\left(\log _{10}(\mathrm{LF})\right)$ for stream-reared Atlantic salmon parr and smolts

\begin{tabular}{|c|c|c|c|c|}
\hline \multirow[t]{2}{*}{ Fin } & \multicolumn{2}{|l|}{ Parr } & \multicolumn{2}{|l|}{ Smolt } \\
\hline & Regression equation & $r^{2}$ & Regression equation & $r^{2}$ \\
\hline Right pectoral & $-56.3+\left(38.4 \times \log _{10}(\mathrm{LF})\right)$ & 0.97 & $9.36+(0.10 \times \mathrm{LF})$ & 0.91 \\
\hline Left pectoral & $-56.1+\left(38.3 \times \log _{10}(\mathrm{LF})\right)$ & 0.96 & $8.49+(0.11 \times \mathrm{LF})$ & 0.92 \\
\hline Right pelvic & $-41.9+\left(28.2 \times \log _{10}(\mathrm{LF})\right)$ & 0.96 & $4.48+(0.08 \times \mathrm{LF})$ & 0.90 \\
\hline Left pelvic & $-42.6+\left(28.5 \times \log _{10}(\mathrm{LF})\right)$ & 0.95 & $4.96+(0.08 \times \mathrm{LF})$ & 0.88 \\
\hline Dorsal & $2.94+(0.12 \times \mathrm{LF})$ & 0.94 & $3.12+(0.12 \times \mathrm{LF})$ & 0.90 \\
\hline Adipose & $-20.6+\left(13.8 \times \log _{10}(\mathrm{LF})\right)$ & 0.90 & $1.11+(0.05 \times \mathrm{LF})$ & 0.81 \\
\hline Caudal & $0.45+(0.18 \times \mathrm{LF})$ & 0.95 & $-2.62+(0.19 \times \mathrm{LF})$ & 0.91 \\
\hline Anal & $2.05+(0.11 \times \mathrm{LF})$ & 0.96 & $3.06+(0.08 \times \mathrm{LF})$ & 0.85 \\
\hline
\end{tabular}

Regression equations were formulated from linear regression analysis of fin length against fork length (dorsal, caudal and anal) or the log transformation of fork length (right pectoral, left pectoral, right pelvic, left pelvic and adipose) for stream-reared parr $(N=120)$, and fin length against fork length for stream-reared smolts $(N=24)$. 
Linear regression analysis was also performed for all stream-reared smolts (Fig. 2 and Table 1). All fins exhibited a linear relationship with fork length, which was different from the relationship in parr. High coefficients of determination $\left(r^{2}=0.80\right)$ indicated a significant relationship between fin lengths and fork length.

Stream-reared parr and smolts exhibited clear differences in fin sizes (Fig. 3). Relative pectoral, pelvic, anal and adipose fin lengths (fin length/fork length) were greater among stream-reared parr than smolts of similar size $(132-173 \mathrm{~mm}$; Mann-Whitney $U$-test, $P<0.05)$. Relative dorsal and caudal fin lengths, however, were not different among stream-reared parr and smolts $(P>0.05)$.

While the data indicate clear differences in fin lengths between stream- and hatcheryreared fish (Figs. 1 and 2), multiple linear regression analyses were not satisfactory due to the high variability in fin lengths of hatchery-reared fish, precluding satisfying the
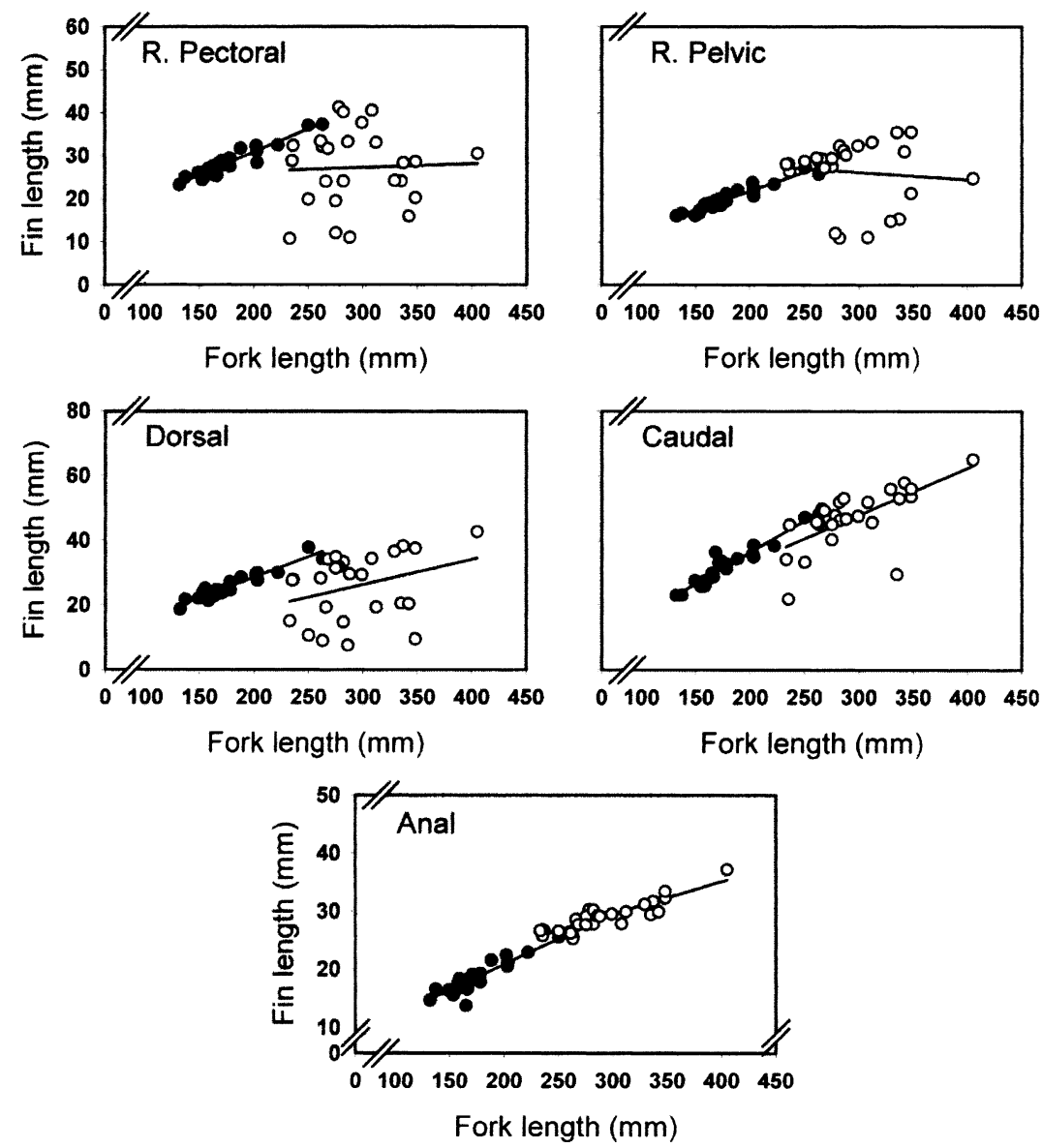

Fig. 2. Regression plots of fin length against fork length (LF) for stream-reared Atlantic salmon smolts $(N=24$; -) sampled from the main stem of the Connecticut River in May 1998, and hatchery-reared smolts $(N=24 ; O)$ sampled from the White River National Fish Hatchery in April 1998. 

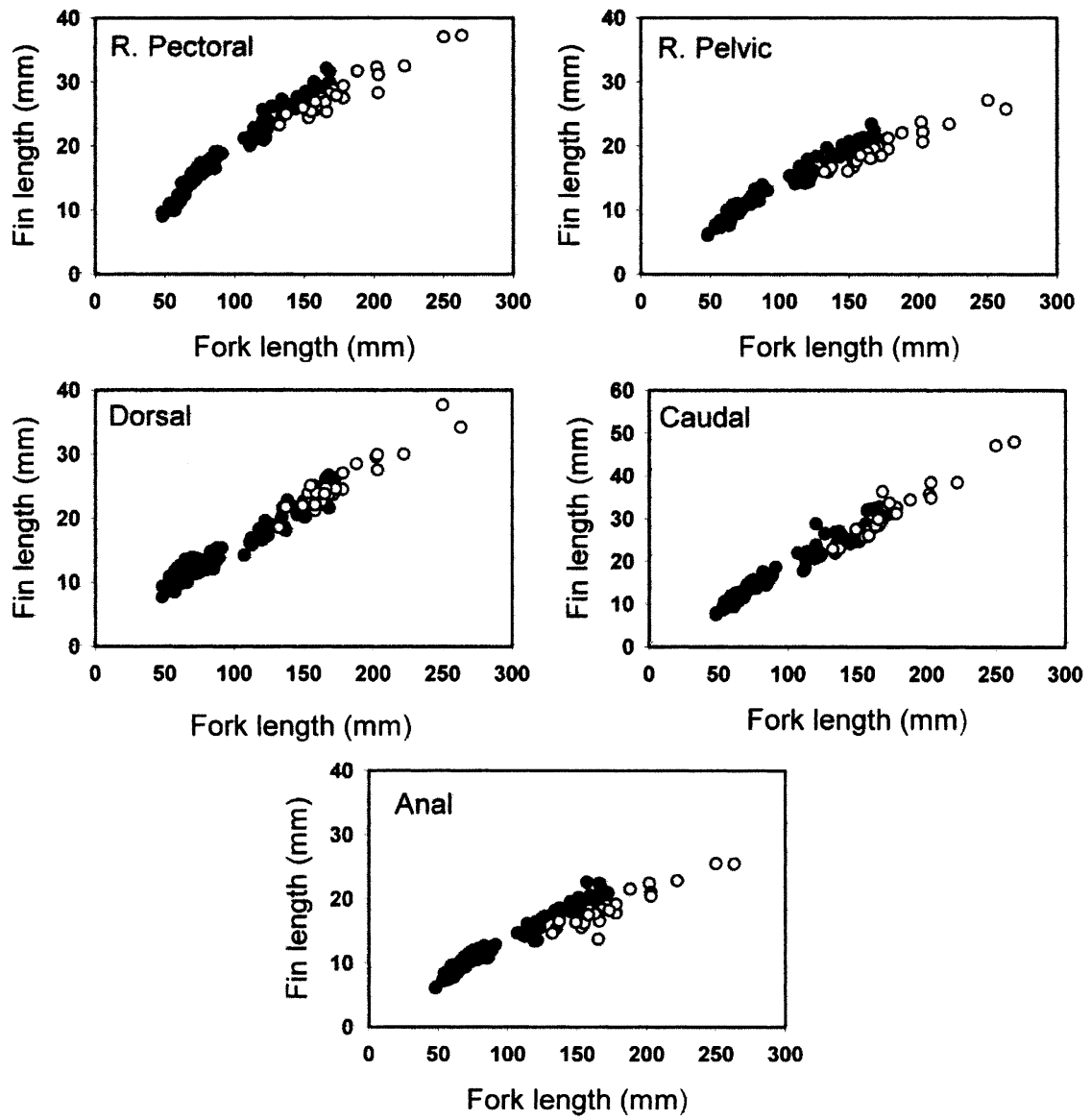

Fig. 3. Scatterplot of fork length against right pectoral, right pelvic, dorsal, caudal and anal fin length for streamreared Atlantic salmon parr (-) sampled from two Connecticut River tributaries in Massachusetts in July and October 1997, and smolts (O) sampled from the main stem of the Connecticut River in May 1998.

assumption of homoscedasticity. Therefore, linear regression equations produced for the fins of stream-reared parr were used to calculate the percent difference (observed fin length/expected) in fin lengths between stream- and hatchery-reared parr. Percent difference in fin length was obtained for each fin of individual hatchery-reared parr. Mean percent difference in fin length was then calculated for each hatchery at the three time points (Fig. 4). Two-way ANOVA on ranks indicated that all fins of hatchery-reared parr became shorter with time $(P<0.05)$. With exception to the anal fins of the Kensington fish, the pelvic, adipose, caudal and anal fins of hatchery-reared parr showed no signs of degeneration by the first sampling period (August 1997), whereas degeneration in the pectoral $(13-20 \%)$ and dorsal $(15-18 \%)$ fins was evident at this time. Throughout the study, the adipose fin was always larger $(8-35 \%)$ in the hatchery-reared parr. By the end of the study (April-May 1998), degeneration was present in every fin except the adipose; 


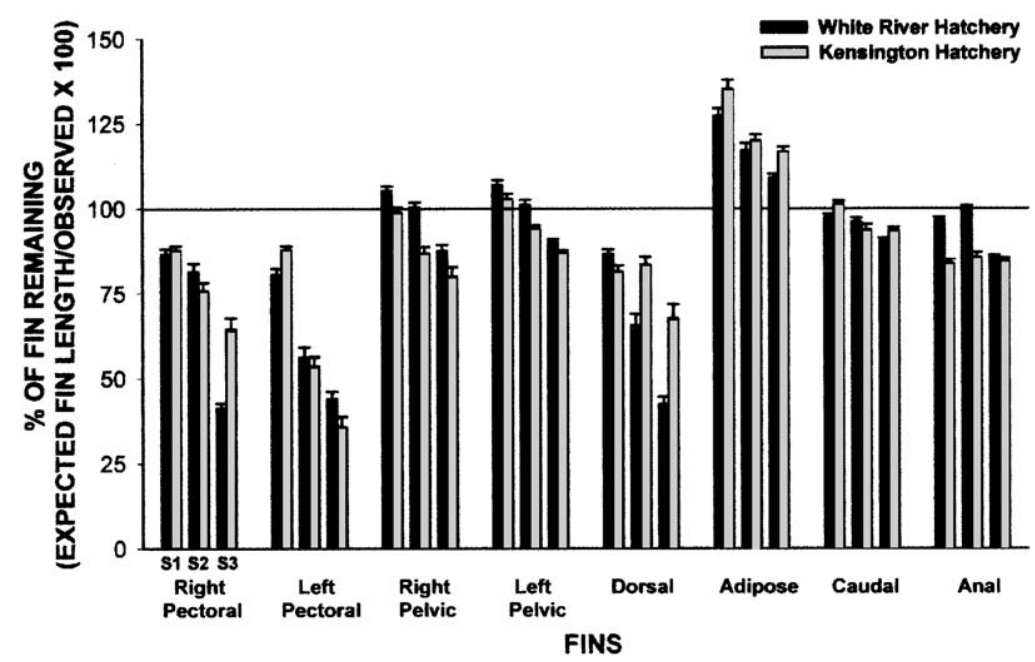

Fig. 4. Bar chart comparing mean relative fin lengths of Atlantic salmon parr from the White River National Fish Hatchery and the Kensington State Salmon Hatchery. Bar heights indicate mean relative fin lengths $(100 \times$ observed fin length/expected) while error bars represent the standard error of the mean. S1= sample period one (August 1997), S2 = sample period two (October 1997), S3=sample period three (April and May 1998). The solid line at the $100 \%$ mark represents mean fin lengths for the stream-reared parr.

with the pectoral $(35-65 \%)$ and dorsal $(32-58 \%)$ fins exhibiting the greatest amount of fin loss.

Differences in fin degeneration were also apparent between fish from each hatchery (Fig. 4). Differences in fin lengths between parr from both hatcheries occurred in the pelvic, dorsal, adipose, anal and caudal fins (two-way ANOVA, $P<0.05$ ), while the pectoral fins did not differ. At the last sampling date, the right pectoral and dorsal fins of parr from the White River hatchery were 23\% and 25\% shorter, respectively, than parr from the Kensington hatchery, while fin loss was approximately equal for the left pelvic, caudal and anal fins. In contrast, by the end of the study, the left pectoral $(9 \%)$ and right pelvic $(8 \%)$ fins were longer in parr from the White River hatchery than the Kensington hatchery. An interaction was found with date and hatchery for the pectoral, dorsal, anal, caudal and right pelvic fins $(P<0.05)$. In hatchery-reared smolts, fin degeneration was most prominent in the pectoral and dorsal fins while the pelvic and caudal fins were in better condition (Fig. 2). The anal fin of smolts showed little sign of degeneration.

\section{Discussion}

Relative fin index (fin length/total length; see Kindschi, 1987) is a method of quantifying fin development that has been used in numerous studies to date (Bosakowski and Wagner, 1994; Barnes et al., 1996; Winfree et al., 1998). The use of fin indices, however, relies on the linear increase of fin length as a function of total length, which may not be the case depending on the species, developmental stage, fin and size range of fish 
sampled. Although dorsal, caudal and anal fin growth exhibited a linear relationship in stream-reared parr, pectoral, pelvic and adipose fins displayed a nonlinear growth pattern. In smolts, however, the relationship was linear for all fins. This may be due to the smaller size range of smolts sampled. Due to the allometric growth pattern of some fins, linear regressions were used to calculate the expected fin length for hatchery-reared parr. The percentage of fin degeneration among individual hatchery-reared parr could then be calculated using these regressions $(100 \times$ observed fin length/expected $)$.

The relative size of the pectoral, pelvic, dorsal, adipose and anal fins was similar for parr collected in the Chickley River and West Brook. Multiple regression analysis indicated that caudal fin lengths of fish from the two streams were different, with a greater relative size in Chickley River parr. The gradient of the Chickley River is approximately twice that of the West Brook and may provide a reason for differences in caudal fin size among fish from the two streams. Caudal fins are actively used for burst swimming (Vogel, 1981), and larger caudal fins among fish from the Chickley River would provide an advantage for swimming against the faster moving water. McLaughlin and Grant (1994) have found caudal fin heights to be larger in brook charr (Salvelinus fontinalis) in faster moving water. By experimentally placing Atlantic salmon and brown trout (Salmo trutta) in raceways with different water velocities, Pakkasmaa and Piironen (2001) determined that caudal fins were larger among fish in faster flowing water after 4 weeks.

Atlantic salmon undergo rapid morphological change in preparation for seaward migration, which has a major impact on condition factor $\left(100\left(\right.\right.$ weight/length $\left.{ }^{3}\right)$; Wedemeyer et al., 1980), and may affect other growth patterns as well. Relative to body length, pectoral, pelvic and anal fins were smaller among smolts than parr. This may be due (in part) to the high growth in body length that occurs during smolting, and may be related to a decreased reliance on these fins for open ocean swimming. In contrast, relative sizes of dorsal and caudal fins were not different among parr and smolts. In the marine environment, Atlantic salmon are pelagic and rely on their caudal fin for propulsion during cruising (Webb, 1994), which may explain the increased size of this fin during smolting. Similarly, the dorsal fin likely acts to stabilize the body during open ocean swimming.

Fin degeneration was widespread among parr in both hatcheries, and fins became shorter with time. Only the pectoral and dorsal fins showed signs of degeneration by the first sampling in August 1997. All fins, however, were shortened by the third sampling period in April-May 1998. The pectoral and dorsal fins were most affected by the hatchery environment and were as much as $60 \%$ shorter than in stream-reared fish by the third sampling. In some instances, the pectoral and dorsal fins exhibited bleeding, exposed fin rays and whitened margins, attributes of hatchery-reared Atlantic salmon (Schneider and Nicholson, 1980; Turnbull et al., 1996). The pelvic and anal fins were 10-20\% shorter by the third sampling, but displayed less extensive trauma than either the pectoral or dorsal fins. The adipose fin of hatchery-reared parr was longer than that of stream-reared parr, and may indicate differences in diet and fat reserves. Although caudal fins of parr exhibited a wide range of susceptibilities from normal to severe degeneration, on average, the hatchery environment affected these fins the least. Variability in caudal fin lengths was the greatest reason for using fork length as the independent variable in the analysis of fin degeneration. Pectoral, pelvic and dorsal fins appeared to be the most affected in hatchery- 
reared smolts. Except for the anal fin, fin degeneration in hatchery-reared smolts varied greatly among individuals. This wide range of fin sizes from normal to severely short may be an indicator that individuals display differences in susceptibility to fin degeneration. In addition, individual fish may vary in their social status and in the aggression they receive from conspecifics.

While fin degeneration was widespread in both hatcheries, it is difficult to pinpoint the causative factors. As mentioned previously, the pectoral and dorsal fins were most prone to degeneration. The dorsal fin has been shown to be a preferential target during aggressive attacks (Abbott and Dill, 1985). In contrast, Turnbull et al. (1998) found pectoral fin erosion to be the result of abrasion with tank walls rather than aggressive attacks. At the conclusion of the study, Kensington parr were being reared in a pond with a pool liner and had pectoral fins that were in better condition than parr from the White River hatchery, which were in a concrete pond. The pool liner at the Kensington River hatchery possibly provided a less abrasive surface, which may have reduced pectoral fin degeneration in these fish. Compared to concrete raceways, cobble substrate provides a less abrasive surface, and has been used successfully to reduce fin erosion in salmonids (Bosakowski and Wagner, 1995; Wagner et al., 1996). Rearing density does not appear to be a factor contributing to fin degeneration since rearing densities were relatively low $(2.8-18.8 \mathrm{~kg}$ $\mathrm{m}^{-3}$ ) compared to studies that have found no effect of rearing density on fin erosion (Soderberg and Krise, 1987; Soderberg and Meade, 1987). The pelvic and anal fins were in good condition compared to the pectoral and dorsal fins. Abbott and Dill (1985) reported no damage in the anal fins of steelhead trout (Oncorhynchus mykiss) and proposed that the anal fin was less susceptible to attack during aggressive encounters. Like the anal fin, the pelvic fins are located in an area that is less susceptible to attack by conspecifics. Due to their location, however, the pelvic and anal fins are prone to abrasion with the tank bottom. The adipose fin tended to be longer in parr from the Kensington hatchery and may imply differences in feeding regimes between the two hatcheries. Condition factor, however, was not different between parr from the two hatcheries ( $P>0.05$, Mann-Whitney $U$-test).

There is no doubt that fin erosion is a common and serious problem affecting hatcheries throughout the world. Optimal results from hatcheries involved in enhancement and restoration of anadromous salmonids rely on maximum survival of stocked fish. Farmer (1994) proposed that recovery of adult Atlantic salmon was dependent on "smolt quality", which is a function of size, weight, condition factor, the incidence of fin erosion and other health-related factors. Fin erosion, especially in the pectoral and dorsal fins, may impair mobility and overall survival in the natural environment (Schneider and Nicholson, 1980). As indicated in the introduction, the pectoral fins of Atlantic salmon parr are essential for station holding in current. Station holding probably becomes less important following smolting, and pectoral fin degeneration among smolts may play less of a role in reducing smolt survival. The fins of hatchery-reared parr became worse with time but not all fins were shortened by the first sampling period (August), which took place 5-6 months after the first feeding. Fry stocking programs often stock before the first feeding, which may be at a time when fin degeneration is minimal. In contrast, fin degeneration was evident in 1year-old parr and 2-year-old smolts. The poor fin condition of many hatchery-reared smolts may be a contributing factor to the relatively poor return rates of hatchery-reared 
fish (McCormick et al., 1998). Determining and alleviating the causes of poor fin development may allow for increased yields of hatchery programs. The current study contributes to determining the causes of fin degeneration in Atlantic salmon by demonstrating the process of natural fin growth, and by establishing the time course and possible causes of fin degeneration in the hatchery environment.

\section{Acknowledgements}

We thank the staff of the White River National Fish Hatchery, US Fish and Wildlife Service, and the Kensington State Hatchery, Connecticut Department of Environmental Protection for their help and cooperation during this study. We would also like to thank Mike O'Dea, Todd Dubreuil and Amy Moeckel for their help with fish collection and sampling. Darren Lerner made many helpful suggestions in review of this manuscript.

\section{References}

Abbott, J.C., Dill, L.M., 1985. Patterns of aggressive attack in juvenile steelhead trout (Salmo gairdneri). Can. J. Fish. Aquat. Sci. 42, $1702-1706$.

Arnold, G.P., Webb, P.W., Holford, B.H., 1991. The role of the pectoral fins in station-holding of Atlantic salmon parr (Salmo salar L.). J. Exp. Biol. 156, 625-629.

Barnes, M.E., Sayler, W.A., Cordes, R.J., 1996. Baffle usage in covered raceways. Prog. Fish-Cult. 58, $286-288$.

Bosakowski, T., Wagner, E.J., 1994. Assessment of fin erosion by comparison of relative fin length in hatchery and wild trout in Utah. Can. J. Fish. Aquat. Sci. 51, 636-641.

Bosakowski, T., Wagner, E.J., 1995. Experimental use of cobble substrates in concrete raceways for improving fin condition of cutthroat (Oncorhynchus clarki) and rainbow trout (O. mykiss). Aquaculture 130, 159-165.

Farmer, G.J., 1994. Some factors which influence the survival of hatchery Atlantic salmon (Salmo salar) smolts utilized for enhancement purposes. Aquaculture 121, 223-233.

Johannsson, N., 1981. General problems in Atlantic salmon rearing in Sweden. Ecol. Bull. (Stockholm) 34, 75 -83.

Kindschi, G.A., 1987. Method for quantifying degree of fin erosion. Prog. Fish-Cult. 49, 314-315.

McCormick, S.D., Hansen, L.P., Quinn, T.P., Saunders, R.L., 1998. Movement, migration, and smolting of Atlantic salmon (Salmo salar). Can. J. Fish. Aquat. Sci. 55, 77-92.

McLaughlin, R.L., Grant, J.W.A., 1994. Morphological and behavioural differences among recently-emerged brook charr, Salvelinus fontinalis, foraging in slow- vs. fast-running water. Environ. Biol. Fishes 39, $289-300$.

Mork, J., Jarvi, T., Hansen, L.P., 1989. Lower prevalence of fin erosion in mature than in immature Atlantic salmon (Salmo salar) parr. Aquaculture 80, 223-229.

Pakkasmaa, S., Piironen, J., 2001. Water velocity shapes juvenile salmonids. Evol. Ecol. 14, 721-730.

Schneider, R., Nicholson, B., 1980. Bacteria associated with fin rot disease in hatchery-reared Atlantic salmon (Salmo salar). Can. J. Fish. Aquat. Sci. 37, 1505-1513.

Soderberg, W., Krise, W.F., 1987. Fin condition of lake trout, Salvelinus namaycush Walbaum, reared at different densities. J. Fish Dis. 10, 233-235.

Soderberg, R.W., Meade, J.W., 1987. Effects of rearing density on growth, survival, and fin condition of Atlantic salmon. Prog. Fish-Cult. 49, 280-283.

Turnbull, J.F., Richards, R.H., Robertson, D.A., 1996. Gross, histological and scanning electron microscopic appearance of dorsal fin rot in farmed Atlantic salmon, Salmo salar L., parr. J. Fish Dis. 19, 415-427.

Turnbull, J.F., Adams, C.E., Richards, R.H., Robertson, D.A., 1998. Attack site and resultant damage during aggressive encounters in Atlantic salmon (Salmo salar L.) parr. Aquaculture 159, 345-353.

Vogel, S., 1981. Life in Moving Fluids: The Physical Biology of Flow. Willard Grant Press, Boston, MA.

Wagner, E.J., Intelmann, S.S., Routledge, D.M., 1996. The effects of fry rearing density on hatchery performance, 
fin condition, and agonistic behavior of rainbow trout Oncorhynchus mykiss fry. J. World Aquac. Soc. 27, $264-273$.

Webb, P.W., 1994. The biology of fish swimming. In: Maddock, L., Bone, Q., Rayner, J.M.V. (Eds.), Mechanics and Physiology of Animal Swimming. Cambridge Univ. Press, New York, pp. 45-62.

Wedemeyer, G.A., Saunders, R.L., Clarke, W.C., 1980. Environmental factors affecting smoltification and early marine survival of anadromous salmonids. Mar. Fish. Rev., U.S. Natl. Mar. Fish. Serv. 42, 1-14.

Winfree, R.A., Kindschi, G.A., Shaw, H.T., 1998. Elevated water temperature, crowding, and food deprivation accelerate fin erosion in juvenile steelhead. Prog. Fish-Cult. 60, 192-199. 